\title{
EFFECT OF SIMULATED MICROGRAVITY ON THE VIRULENCE PROPERTIES OF THE OPPORTUNISTIC BACTERIAL PATHOGEN STAPHYLOCOCCUS AUREUS
}

\author{
Helena Rosado \\ School of Pharmacy, University of London, United Kingdom \\ helena.rosado@pharmacy.ac.uk \\ Paul D. Stapleton \\ School of Pharmacy, University of London, United Kingdom \\ paul.stapleton@pharmacy.ac.uk \\ Peter W. Taylor \\ School of Pharmacy, University of London, United Kingdom \\ peter.taylor@pharmacy.ac.uk
}

\begin{abstract}
Extended manned space flight will result in a diminution of immune status and cause profound changes in the human bacterial microbiota, leading to increased risk of infection. Experiments conducted during short-term flight suggest that growth in microgravity leads to increases in bacterial antibiotic resistance and to cell wall changes. Growth under low-shear modelled microgravity (LSMMG) indicated that a reduced gravitational field acts as an environmental signal for expression of enhanced bacterial virulence in Gram-negative pathogens. We examined the effect of simulated microgravity on parameters of virulence in clinical isolates of Staphylococcus aureus. Three strains were grown under LSMMG in a High Aspect Ratio Vessel and compared with cells grown under normal gravity (NG) in the same vessel. There were no significant differences in the antibiotic susceptibility, growth rate or morphology of staphylococci grown under LSMMG compared to NG. LSMMGinduced reductions in synthesis of the pigment staphyloxanthin were noted. Strains secreted less protein under LSMMG and reductions in haemolysin secretion were found. Reduced expression of the major virulence determinant $\alpha$-toxin in the microgravity environment was found by gene amplification. Thus, in contrast to published data on Gram-negative pathogens, simulated microgravity reduces the expression of key virulence determinants of $S$. aureus.
\end{abstract}

\section{INTRODUCTION}

Plans to resume manned missions to the Moon and to launch manned flights from the lunar surface for the purpose of Martian exploration will provide enormous challenges to those responsible for the provision of biomedical support. In addition to the well-documented extended flight risks associated with microgravity-induced decreases in bone mineral density, psychological problems due to isolation, noise, confinement and a restricted working environment, muscular atrophy, decreased cardiovascular performance, and prolonged exposure to ionising and non-ionising forms of radiation [1], microbial infections will almost certainly arise due to decreases in immune function. Analysis of medical events among astronauts aboard the Russian space station Mir from March
1995 to June 1998 indicated that a significant number of episodes of infection occurred, including conjunctivitis and acute respiratory and dental infections [2]. In addition, injury and trauma, such as lacerations and open fractures, are likely to occur on long missions and will require prophylactic administration of antibiotics to prevent serious wound infection.

On-board infections will most likely originate from the endogenous human flora of the crew, although microbial contamination of the fabric of the spacecraft and its air and water supply has been noted [3]. Even brief space flight induces changes in the composition of the intestinal [4], oral $[5,6]$ and nasal [6] bacterial microflora and crew members are susceptible to in-flight crosscontamination with opportunistic pathogens such as Staphylococcus aureus via the upper respiratory 
tract [6]. The negative impact of space travel on the function of cells of the immune system $[7,8]$ are exacerbated by reductions in the diversity of the normal bacterial flora and a relative increase in the numbers of opportunistic pathogens at sites such as the nasal passage [9].

Treatment of on-board infections could be compromised by reversible increases in antibiotic resistance. Experiments aboard Soviet $[10,11]$ and American [12,13] vessels have indicated that the antibiotic susceptibility of both Gram-positive and Gram-negative bacteria may be significantly reduced during flight. For example, the minimum inhibitory concentration (MIC) of colistin and kanamycin required to kill Escherichia coli increased fourfold in comparison to ground experiments when determined aboard Salyut 7; the reduction in oxacillin, erythromycin and chloramphenicol susceptibility of a S. aureus isolate was accompanied by large increases in the thickness of the cell wall, an effect often intimately associated with changes in sensitivity to antibiotics. These on-board experiments strongly suggest that growth of these medically important bacteria in a microgravity environment changes the bacterial phenotype in a way that may render them antibiotic resistant. Also of concern for the well being of flight crew is the gathering evidence that microgravity may act as an environmental signal for expression of enhanced bacterial virulence [14]. Nickerson and coworkers [15] determined that Salmonella enterica serovar Typhimurium grown under low-shear modelled microgravity (LSMMG) using a high aspect ratio vessel (HARV) displayed enhanced virulence for mice compared to bacteria grown under normal gravity: LSMMG-grown cells had a decreased $\mathrm{LD}_{50}$, produced shortened time to death of infected test animals, and more readily colonized the liver and spleen. The processes involved in LSMMG-induced gene regulation appear to be novel and may be microgravityspecific [16]. We believe that there is an urgent need for these pioneering studies to be extended to include other groups of pathogens, particularly opportunistic Gram-positive bacteria frequently associated with the human microflora and likely to pose a risk of infection on extended missions. We have therefore investigated the effect of simulated microgravity on the parameters of antibiotic susceptibility and virulence in clinical isolates of the Gram-positive pathogen S. aureus.

\section{MATERIALS AND METHODS}

Bacterial strains and reagents. The methicillin susceptible S. aureus (MSSA) isolates RF1, RF6 and RF11 were from clinical samples processed at the Royal Free Hospital, London and were a gift from J.M.T. Hamilton-Miller. The following companies kindly provided the antibiotics used in this study: GlaxoSmithKline (flucloxacillin), Eli Lilly (vancomycin hydrochloride) and Sanofi Aventis (erythromycin).

Bacterial culture. Bacterial cells were grown in Müller-Hinton (MH) broth (Oxoid, Basingstoke, UK) using Synthecon RCCS-1 HARVs (obtained from Cellon S.A., Bereldange, Luxembourg) housed in a $37^{\circ} \mathrm{C}$ incubator. Shake flask MH broth cultures were incubated for $16 \mathrm{~h}$ at $37^{\circ} \mathrm{C}$, diluted 1:50 in fresh $\mathrm{MH}$ broth and transferred into the bioreactor compartment. Care was taken to ensure that the reactor was completely filled with medium and that there was a complete absence of air bubbles. The bioreactors were then orientated to grow cells under conditions of LSMMG (rotation about the horizontal axis) or normal gravity (NG; rotation about the vertical axis). In all experiments, LSMMG and NG cultures were grown simultaneously with a rotation rate of $25 \mathrm{rpm}$ for up to $24 \mathrm{~h}$. To determine growth rates, samples were removed via the sampling port and the $\mathrm{OD}_{600}$ measured. In all other experiments, cells were harvested after $24 \mathrm{~h}$ incubation. The culture supernatants were concentrated 30-fold using Vivaspin 20 ultrafiltration spin columns (Generon Ltd., Berkshire, UK).

MIC. The MICs for flucloxacillin, vancomycin and erythromycin against the three MSSA isolates were determined by the broth dilution method using serial twofold dilutions of the antibiotics. Assays were performed in 96-well microtitre trays with an inoculum of $10^{4} \mathrm{CFU}$ in $100 \mu 1$ of $\mathrm{MH}$ broth. $S$. aureus ATCC29213 was used as a reference strain to ensure comparability with published data. MIC values were obtained after incubation at $37^{\circ} \mathrm{C}$ for $24 \mathrm{~h}$. The MIC was determined to be the lowest antibiotic concentration at which no visible bacterial growth occurred.

Electron microscopy. For scanning electron microscopy (SEM), bacteria were recovered by centrifugation and washed twice with phosphate buffered saline (PBS). Cells were fixed in $1.5 \% \mathrm{w} / \mathrm{v}$ glutaraldehyde for at least $2 \mathrm{~h}$ at room temperature, 
washed once with $70 \%$ ethanol and twice in $100 \%$ ethanol. Air-dried, gold-coated preparations were examined using a FEI XL30 scanning electron microscope. For transmission electron microscopy (TEM), the cells were recovered by centrifugation and washed twice in PBS. Bacteria were fixed in $1.5 \% \mathrm{w} / \mathrm{v}$ glutaraldehyde for at least $2 \mathrm{~h}$ at room temperature, treated with osmium tetroxide and embedded in epoxy resin. Sectioning and staining with uranyl acetate was followed by Reynolds' lead citrate. Ultra-thin sections were viewed and photographed using a Philips 201 transmission electron microscope.

Assays for staphylococcal haemolytic activity. Defibrinated sheep or rabbit blood $(10 \mathrm{ml}$; E\&O Laboratories, Bonnybridge, UK) was centrifuged $(1,000 \mathrm{~g}, 15 \mathrm{~min})$, the erythrocytes washed three times with PBS and then suspended in cold sterile PBS to a concentration of $1 \% \mathrm{v} / \mathrm{v}$. A normalized volume of culture supernatant was added to aliquots of this suspension to give a combined final volume of $1.5 \mathrm{ml}$ and the mixtures incubated at $37^{\circ} \mathrm{C}$ for 30 min, followed by $25 \mathrm{~min}$ at $4^{\circ} \mathrm{C}$. After centrifugation to remove intact cells, the degree of erythrocyte lysis was determined spectrophotometrically $\left(\mathrm{A}_{540 \mathrm{~nm}}\right)$.

Extraction and quantification of carotenoids. Staphyloxanthin and intermediate carotenoids were extracted and quantified according to Wieland and coworkers [17]. Bacteria were harvested by centrifugation $(3,000 \mathrm{~g}, 10 \mathrm{~min})$ and washed twice with PBS. The packed cells were either extracted immediately or could be maintained at $-20^{\circ} \mathrm{C}$ for up to 3 months without their carotenoid content being affected. The cells (10 mg dry weight) were suspended in $500 \mu \mathrm{l}$ of methanol, held at $55^{\circ} \mathrm{C}$ in water bath for 5 minutes, cooled and extracts obtained by centrifugation. The extraction was repeated twice, until no further pigment could be extracted. Carotenoids were estimated quantitatively by measuring absorbance of solutions at $462 \mathrm{~nm}$, the absorbance maximum of the primary carotenoid pigment staphyloxanthin.

Expression of virulence determinants. Proteins were separated by SDS-polyacrylamide gel electrophoresis (SDS-PAGE); the concentration of acrylamide used was $10 \% \mathrm{w} / \mathrm{v}$. Proteins were visualised by staining with Coomassie blue.

\section{RESULTS AND DISCUSSION}

There are a number of studies demonstrating that a range of bacteria grown under batch culture conditions during space flight yield higher final cell concentrations and total biomass, have increased growth rate and a shorter lag phase in comparison to terrestrial laboratory cultures [18-20]. These effects are attributed in the main to the influence of reduced gravity and this contention is supported by observations of bacterial growth under LSMMG. Thus, the Gram-negative bacteria Salmonella enterica [21] and E. coli [22] have been shown to display increased rates of division and reach a higher cell density under LSMMG, although these effects could not be demonstrated with Pseudomonas aeruginosa [23]. These studies were undertaken using minimal salts medium: when $S$. enterica was examined following growth in complex Luria-Bertani broth, the growth kinetics of LSMMG-grown cells were identical to those obtained under NG conditions [21]. As changes in growth kinetics induced by LSMMG may impact on other parameters of interest, we compared the growth rates of $S$. aureus grown under NG and LSMMG (Fig. 1). No differences in growth kinetics over the $24 \mathrm{~h}$ culture period were seen with any of the three clinical isolates examined. As staphylococci have complex nutritional requirements, these experiments could not be undertaken using chemically defined minimal salts media. Thus, our data obtained with nutritionally complex MH broth lend some support to the view that the combination of minimal medium and LSMMG induce increased metabolic activity that drives growth [24].

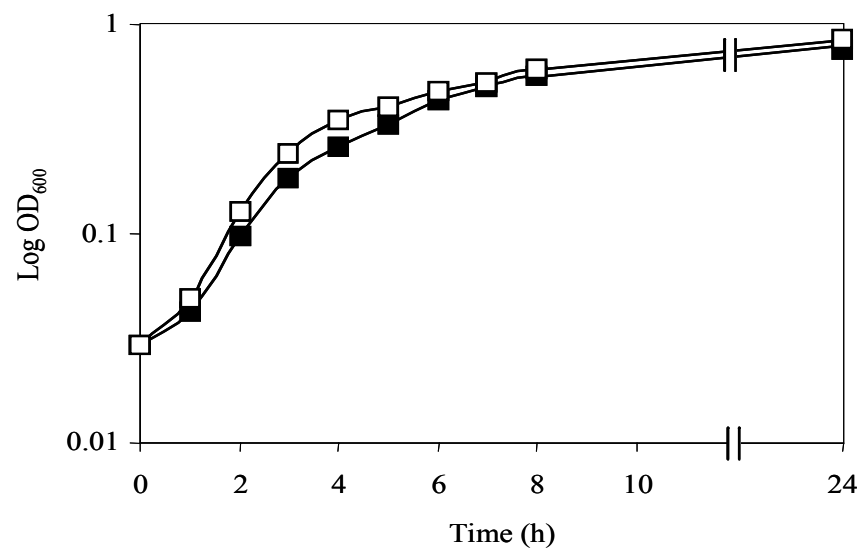

Fig. 1: Growth kinetics of S. aureus RF1 under normal gravity (घ) and simulated microgravity ( $\square$ ). Similar growth curves were obtained for isolates RF6 and RF11. 
There were also no discernable differences in staphylococcal cell morphology as revealed by SEM (Fig. 2) or TEM (Fig. 3). This is in marked contrast to results obtained with a $S$. aureus strain isolated from the automicroflora of the astronaut $\mathrm{J}$. L. Crétien; when cultured in nutritionally complex medium aboard Salyut 7 in July 1982, electron microscopy revealed large increases in the thickness of the cell wall in comparison to the earth control $[10,12]$. The reasons for this disparity are unclear but factors other than microgravity may have been brought to bear during the space flight experiments.
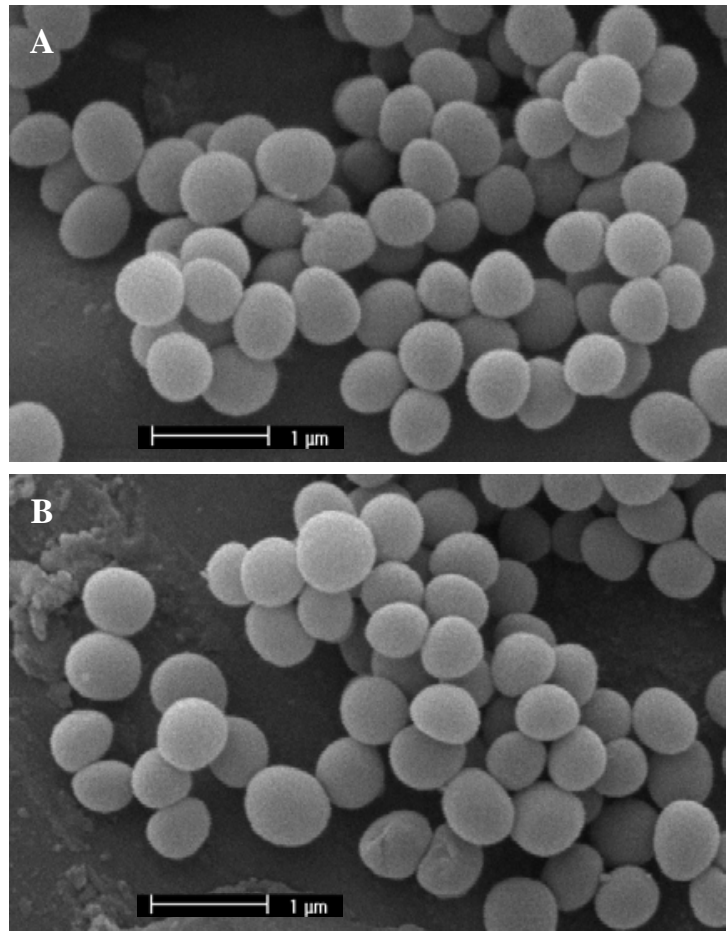

Fig. 2: Scanning electron microscopy images of S. aureus RF6 grown under normal gravity (A) and simulated microgravity (B).

In marked contrast to in-flight investigations conducted in nutritionally complex medium with the Crétien S. aureus isolate [10,12], we found no changes in the susceptibility of RF1, RF6 and RF11 to the macrolide antibiotic erythromycin, the $\beta$ lactam flucloxacillin and the glycopeptide vancomycin (Table 1). These agents were selected for investigation because they interact with different targets in the bacterial cell: erythromycin interrupts the early stages of protein synthesis by binding to the $50 \mathrm{~S}$ ribosomal subunit whereas flucloxacillin and vancomycin interfere with different steps in cell wall peptidoglycan synthesis.
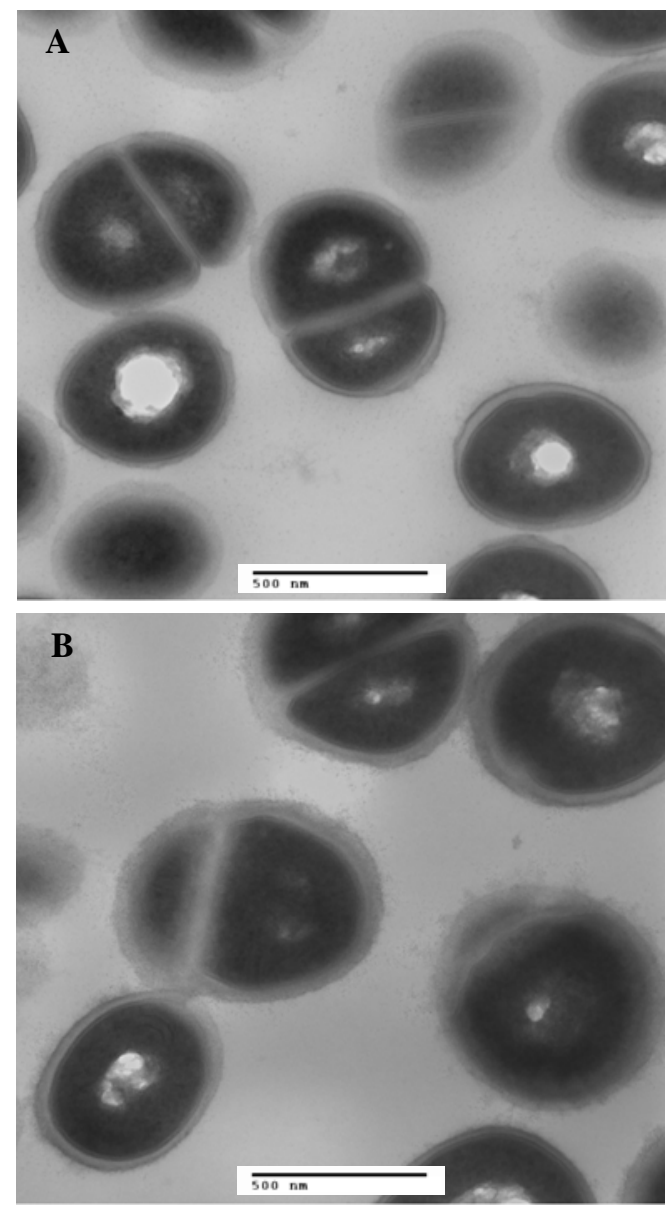

Fig. 3: Transmission electron microscopy images of sections of S. aureus RF6 grown under normal gravity (A) and simulated microgravity (B).

\begin{tabular}{|c|c|c|c|c|c|c|}
\hline \multirow{3}{*}{$\begin{array}{c}\text { Antimicrobial } \\
\text { Agent }\end{array}$} & \multicolumn{6}{|c|}{ Minimum inhibitory concentration $(\mathrm{mg} / \mathrm{L})$} \\
\hline & \multicolumn{2}{|c|}{ RF1 } & \multicolumn{2}{|c|}{ RF6 } & \multicolumn{2}{|c|}{ RF11 } \\
\hline & $\mathrm{NG}$ & LSMMG & $\mathrm{NG}$ & LSMMG & NG & LSMMG \\
\hline Erythromycin & 1 & 1 & 0.25 & 0.12 & $>128$ & $>128$ \\
\hline Flucloxacillin & 0.25 & 0.12 & 0.25 & 0.25 & 0.12 & 0.12 \\
\hline Vancomycin & 1 & 1 & 0.5 & 0.5 & 1 & 1 \\
\hline
\end{tabular}

Table 1: Influence of simulated microgravity on the susceptibility of S. aureus isolates RF1, RF6 and RF11 to antibiotics (NG, normal gravity; LSMMG, low-shear modelled microgravity). 
Growth in a microgravity environment had an impact on a number of factors associated with the virulence of $S$. aureus. The majority of $S$. aureus strains produce carotenoid pigments that impart the golden hue to colonies of this pathogen; the main pigment is staphyloxanthin, a triterpenoid esterified with a C15 fatty acid [25]. A recent study has linked carotenoid pigment synthesis to staphylococcal virulence; mutants unable to synthesise these molecules have impaired survival within neutrophils and are less pathogenic in a mouse subcutaneous abscess model [26]. All three strains that we examined produced less staphyloxanthin when grown under simulated microgravity compared to NG-grown cells (Fig. 4).

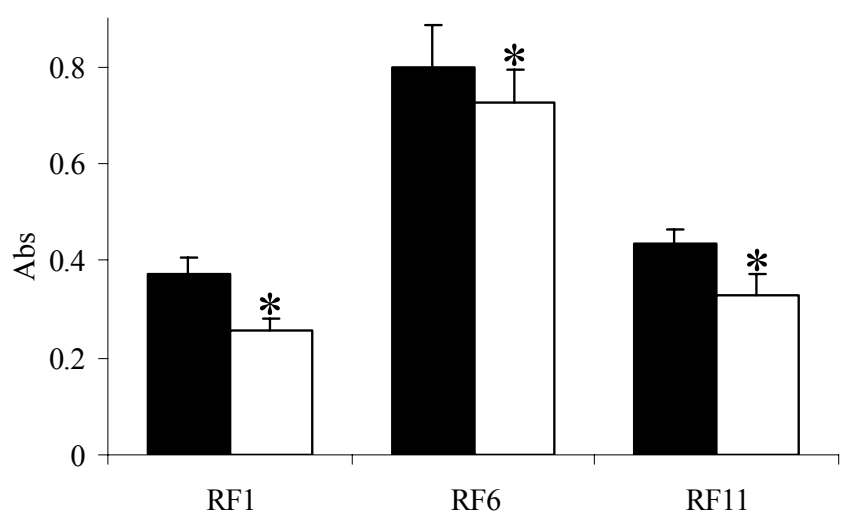

Fig. 4: Production of staphyloxanthin by $S$. aureus isolates grown under normal gravity (-) and simulated microgravity ( $\square$ ). Error bars represent 1SD; $n=6$. *Paired Student's $t$ test, $\mathrm{p}<0.01$.

Staphylococcal pathogenesis is multifactorial and involves secreted proteins that include cytotoxins, tissue-degrading enzymes and superantigens. In addition, cell surface-bound proteins that recognize adhesive matrix molecules such as fibronectin- and collagen-binding protein, along with cell surface components such as the capsule and peptidoglycan, play a key role in determining the capacity of staphylococci to cause disease in humans. Secreted proteins enable the organism to attack the cellular and structural elements of diverse tissues and organs of the infected host and contribute to the spread of the pathogen and its ability to produce symptoms of disease. We have therefore focused our attention on some of these key secreted virulence determinants. The three isolates secrete a wide array of proteins into the surrounding medium and there are clear differences in protein secretion patterns between these strains (Fig. 5). Microgravity cultures secreted less protein than NG-cultured bacteria and the quantity of some individual proteins recovered from the growth medium was markedly reduced. The largest reduction in protein secretion occurred with RF6 (Fig. 5). Interestingly, the secretion of a few proteins was increased under LSMMG: for example, RF6 and RF11 appeared to increase the secretion of a protein with a molecular mass of ca $24 \mathrm{kDa}$. We are in the process of identifying the nature of this protein.

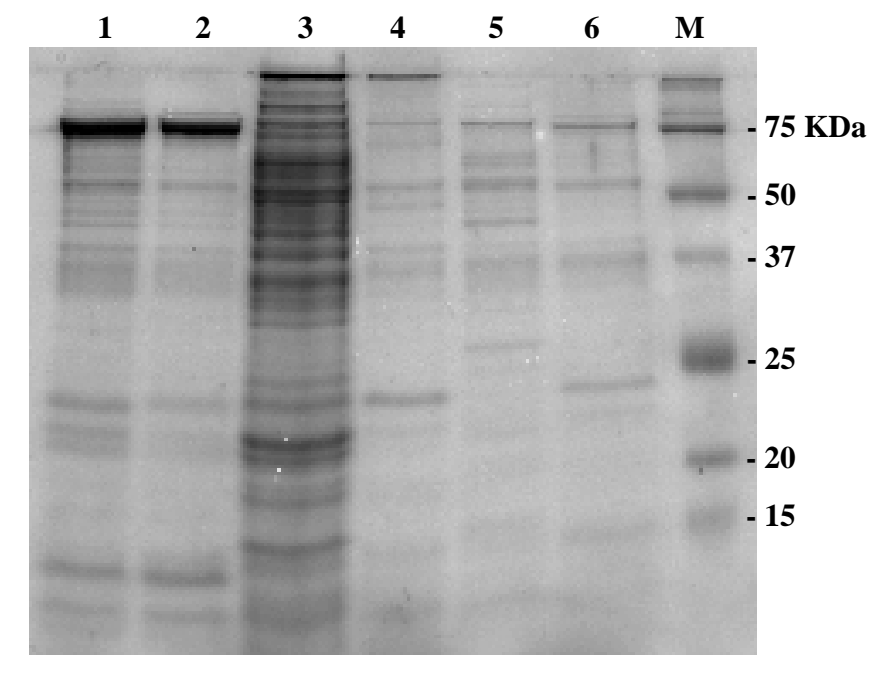

Fig. 5: SDS-PAGE of proteins secreted by S. aureus isolates visualised with Comassie blue. Cells were grown under normal gravity (NG) and simulated microgravity (LSSMG). Lanes: (1) RF1 NG; (2) RF1 LSSMG; (3) RF6 NG; (4) RF6 LSSMG; (5) RF11 NG; (6) RF11 LSSMG; (7) Molecular weight marker.

Most S. aureus isolates secrete one or more cytotoxic proteins that have the capacity to lyse red blood cells. $\alpha$-toxin, the hla gene product, is one of the most potent bacterial toxins known and contributes significantly to morbidity and mortality in human infections [27]. A significant number of $S$. aureus strains produce additional haemolysins such as $\beta$-toxin, $\delta$-toxin, $\gamma$-toxin and other less wellcharacterised biocomponent toxins [27]. The three isolates that we have examined secreted toxins that lysed erythrocytes from sheep blood (Fig. 6a); all the major membrane-active staphylococcal exotoxins possess lytic activity against erythrocytes of this animal species $[27,28]$. Growth under LSMMG reduced the expression of sheep erythrocyte haemolysins in all isolates; with RF6 the effect was marked with toxin secretion almost completely absent. As the $\beta$-haemolysin, in contrast to the $\alpha$ - 
and $\delta$ - forms, is unable to lyse rabbit erythrocytes [28], we examined the capacity of culture supernatants to lyse red cells from this animal species (Fig. 6b). LSMMG-grown bacteria possessed less haemolytic activity and the largest difference was again found with strain RF6; comparison of Fig. $6 \mathrm{a}$ and $6 \mathrm{~b}$ indicates that $\beta$-toxin activity made a significant contribution to the overall lytic profile of RF6 against sheep erythrocytes.
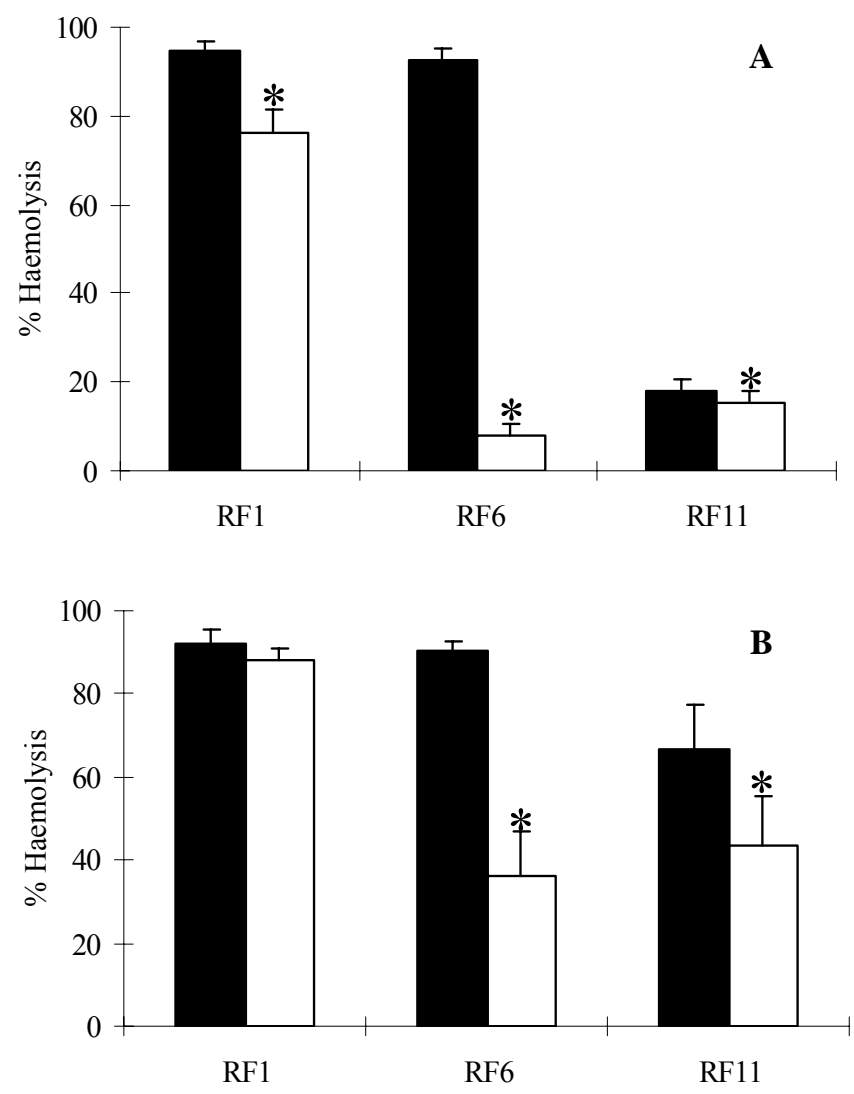

Fig. 6: Secretion of sheep (A) and rabbit (B) erythrocyte haemolysins by $S$. aureus strains grown under normal gravity (ם) and simulated microgravity ( $\square$ ). Error bars represent $1 \mathrm{SD} ; \mathrm{n}=5-6$. *Paired Student's $t$ test, $\mathrm{p}<0.01$.

Few studies have been undertaken to determine the effect of reduced gravitational vectors on the capacity of pathogenic bacteria to cause infection, a factor that may impact on the well being of flight crew with poor immune status. Nickerson and colleagues $[15,24]$ have provided strong evidence that growth in LSMMG substantially increases the lethality of $S$. enterica for mice and increased their capacity to survive in stressed environments, including survival within macrophages. DNA microarray analysis determined that LSMMG differentially regulated the expression of a large number of genes of functional diversity; although the regulatory elements of the LSMMG-mediated phenotype have yet to be identified, there is evidence that the ferric uptake regulator fur is involved in the LSMMG response [16]. As the virulence of Gram-negative pathogens such as $S$. enterica is less reliant on the elaboration of extracellular proteins that damage the infected host than specialised Gram-positive pathogens such as members of the streptococci and staphylococci, we examined the effect of LSMMG on the expression of factors known to mediate the pathogenesis of $S$. aureus. As these organisms constitute a ubiquitous threat to human health in a variety of scenarios, modulation of virulence by mechanical stimuli such as microgravity should throw light on those factors that mediate their capacity to cause disease. Although we have not directly measured LSMMGinduced changes in the infectivity of staphylococci, we have shown that, in sharp contrast to the data produced with Gram-negative bacteria, factors that correlate with virulence are down regulated to a greater or a lesser extent by LSMMG cultivation. Moreover, we found no evidence that microgravity decreased the susceptibility of $S$. aureus to antibiotics and it is difficult to reconcile this outcome with the experiments conducted aboard Salyut 7, Challenger and Discovery in the period 1982-1992, save that influences other than gravity may play a role in determining outcome in the space environment [29]. We are currently attempting to determine the underlying regulatory processes that are responsible for the expression of this interesting bacterial phenotype.

\section{REFERENCES}

1. Grigoriev AI, Kozlovskaya IB, Potapov AN. Goals of biomedical support of a mission to Mars and possible approaches to achieving them. Aviat Space Environ Med 2002;73:379384.

2. Ball JR, Evans $\mathrm{CH}$. Safe passage: astronaut care for exploration missions. Washington DC: National Academy Press; 2001.

3. Castro VA, Thrasher AN, Healy M, Ott CM, Pierson DL. Microbial characterization during early habitation of the International Space Station. Microb Ecol 2004;47:119-126. 
4. Lencner AA, Lencner CP, Mikelsaar ME, Tjuri ME, Toom MA, Valjaots ME, Silov VM, Liz'ko NN, Legenkov VI, Reznikov IM. Die quantitative Zusammensetzung der Lactoflora des Verdauungstrakt vor und nach kosmischen Flügen unterschiedlicher Dauer. Nahrung 1984;28:607-613.

5. Brown LR, Fromme WJ, Handler SF, Wheatcroft MG, Johnston DA. Effect of Skylab missions on clinical and microbiologic aspects of oral health. J Amer Dent Assoc 1976;93:357363.

6. Decelle JG, Taylor GR. Autoflora in the upper respiratory tract of Apollo astronauts. Appl Environ Microbiol 1976;32:659-665.

7. Hales NW, Yamauchi K, Alicea A, Sundaresan A, Pellis NR, Kulkarni AD. A countermeasure to ameliorate immune dysfunction in in vitro simulated microgravity environment: role of cellular nucleotide nutrition. In Vitro Cell Dev Biol Anim 2002;38:213-217.

8. Kaur I, Simons ER, Castro VA, Ott, CM, Pierson DL. Changes in monocyte functions of astronauts. Brain Behav Immun 2005;19:547-54.

9. Nefedov YG, Shilov VM, Koustantinova IV, Zaloguev SN. Microbiological and immunological aspects of extended manned space flights. Life Sci Space Res 1971;9:11-16.

10. Tixador R, Richoilley G, Gasset G, Planel H, Moatti N, Lapchine L, Enjalbert L, Raffin J, Bost R, Zaloguev SN, Bragina MP, Moroz AF, Antsiferova NG, Kirilova FM. Preliminary results of Cytos 2 experiment. Acta Astronaut 1985;12:131-134.

11. Tixador R, Richoilley G, Gasset G, Templier J, Bes JC, Moatti N, Lapchine L. Study of minimal inhibitory concentration of antibiotics on bacteria cultured in vitro in space (Cytos 2 experiment). Aviat Space Environ Med 1985;56:748-751.

12. Lapchine L, Moatti N, Gasset G, Richoilley G, Templier J, Tixador R. Antibiotic activity in space. Drugs Exptl Clin Res 1985;12:933-938.

13. Tixador R, Gasset G, Eche B, Moatti N, Lapchine L, Woldringh C, Toorop P, Moatti JP, Delmotte F, Tap G. Behavior of bacteria and antibiotics under space conditions. Aviat Space Environ Med 1994;65:551-556.

14. Nickerson CA, Ott, CM, Wilson JW, Ramamurthy R, LeBlanc L, Höner zu Bentrup $\mathrm{K}$, Hammond T, Pierson DL. Low-shear modeled microgravity: a global environmental regulatory signal affecting bacterial gene expression, physiology, and pathogenesis. J Microbiol Methods 2003;54:1-11.

15. Nickerson CA, Ott CM, Mister SJ, Morrow BJ, Burns-Keliher L, Pierson DL. Microgravity as a novel environmental signal affecting Salmonella enterica serovar Typhimurium virulence. Infect Immun 2000;68:3147-3152.

16. Wilson JW, Ramamurthy R, Porwollick S, McClelland M, Hammond T, Allen P, Ott CM, Pierson DL, Nickerson DL. Microarray analysis identifies Salmonella genes belonging to the low-shear modeled microgravity regulon. Proc Natl Acad Sci USA 2002;99:13807-13812.

17. Wieland B, Feil C, Gloria-Maercker E, Thumm G, Lechner M, Bravo J-M, Poralla K, Götz F. Genetic and biochemical analyses of the biosynthesis of the yellow carotenoid 4,4'diaponeurosporene of Staphylococcus aureus. J Bacteriol 1994;176:7719-7726.

18. Mennigmann HD, Lange M. Growth and differentiation of Bacillus subtilis under microgravity conditions. In: Longdon N, David V (Eds.), Biorack on Spacelab D1: an overview of the first flight of Biorack, an ESA facility for Life Sciences Research in Microgravity, ESA SP-1091. Kluver, Noordwijk, Netherlands, 1988, pp37-44.

19. Klaus D, Simske S, Todd P, Stodieck L. Investigation of space flight effects on Escherichia coli and a proposed model of underlying physical mechanisms. Microbiology 1997;143:449-455.

20. Kacena MA, Merrell GA, Manfredi B, Smith EE, Klaus DM, Todd P. Bacterial growth in space flight: logistic growth curve parameters for Escherichia coli and Bacillus subtilis. Appl Microbiol Biotechnol 1999;51:229-234.

21. Wilson JW, Ott CM, Ramamurthy R, Porwollick $\mathrm{S}$, McClelland M, Pierson DL, Nickerson CA. Low-shear modeled microgravity alters the Salmonella enterica serovar Typhimurium stress response in a RpoS-independent manner. Appl Environ Microbiol 2002;68:5408-5416.

22. Fang A, Pierson D, Mishra S, Koenig D, Demain A. Effect of simulated microgravity and shear stress on microcin B7 production by Escherichia coli and on its excretion into the medium. Appl Environ Microbiol 1997;63:4090-4092. 
23. Guadarrama S, Pulcini ED, Broadaway SC, Pyle $\mathrm{BH}$. Pseudomonas aeruginosa growth and production of exotoxin A in static and modified microgravity environments. Gravit Space Biol 2005; 18:85-86.

24. Nickerson CA, Ott CM, Wilson JW, Ramamurthy R, Pierson DL. Microbial responses to microgravity and other low-shear environments. Microbiol Molec Biol Rev 2004;68:345-361.

25. Pelz A, Wieland K-P, Putzbach K, Hentschel P, Albert K, Götz F. Structure and biosynthesis of staphyloxanthin from Staphylococcus aureus. J Biol Chem 2005;280:32493-32498.

26. Lui GY, Essex A, Buchanan JT, Datta V, Hoffman HM, Bastian JF, Fierer J, Nizet V. Staphylococcus aureus golden pigment impairs neutrophil killing and promotes virulence through its antioxidant activity. J Exp Med 2005;202:209-215.

27. Bohach GA. Staphylococcus aureus exotoxins. In: Fischetti VA, Novick RP, Ferretti JJ, Portnoy DA, Rood JI (Eds.), Gram-positive pathogens. ASM Press, Washington D C, 2006, pp464-477.

28. Marks J, Vaughan ACT. Staphylococcal $\delta-$ haemolysin. J Path Bact 1950;62:597-615.

29. Taylor PW, Sommer AP. Towards rational treatment of bacterial infections during extended space travel. Int $\mathrm{J}$ Antimicrob Agents 2005;26:183-187. 